persuaded of the merits of this somewhat abused diagnostic technique.

That the authors have been able to accomplish this mammoth task including a useful bibliography inside 300 pages is a remarkable compliment to their selective judgement as well as to the admirable brevity and readability of their literary style. This further edition of an authoritative, compact and readable book will prove even more successful than its predecessors and well merits its obligatory place in every general medical as well as neurological and psychiatric library.

G. STERN

University College Hospital, London WCl

\section{A Colour Atlas of Gynaecological Surgery. Volume 5. Infertility Surgery}

By David H. Lees and Albert Singer. Pp. 200, illustrated. Wolfe Medical Publications, London, 1981. £28.00.

This volume in the 6-volume series on Gynaecological Surgery deals with the operative management of infertility. Although it is mainly devoted to surgical operations and techniques, it includes useful chapters on diagnosis and management; techniques for investigations and diagnosis of utero-tubal disease; psychological factors in infertility surgery, in vitro fertilization and embryo transfer; and artificial insemination.

The general overview of causes of infertility provided in the first chapter is fairly comprehensive, with the exception of the post-coital test and cervical mucus sperm hostility, about which the authors are rather too dismissive. The one page chapter on psychological factors in infertility surgery provides a sensible checklist of the prerequisites which should be satisfied before embarking on such surgery. However, it does not sufficiently emphasize the importance of explaining the success rate of the proposed procedure to the patient and her partner, in order to enable her to come to a well-informed decision about the operation.

The major part of the book is devoted to providing detailed stepby-step descriptions of the various infertility operations, including a chapter on micro-surgical techniques. All these descriptions are based on serial colour photographs, with superimposed arrows and reference markers, of actual operations, which were such a successful feature of the earlier volumes.

This volume, as its predecessors, will be extremely useful for training gynaecologists and deserves a place on the reference shelves of Departmental Libraries or Postgraduate Medical Centres.

$$
\text { P. CuRzen }
$$

Westminster Medical School, London SW1

\section{Doctors and Management Skills \\ By Frada Eskin. Pp 78. MCB Publications, Bradford, 1981. £6.95.}

Since 1974 clinicians have been formally involved in NHS management and from April 1982 they have been even more involved. Whereas NHS authorities and organizations such as the King's Fund have tried, successfully in my view, to assist clinicians fulfill their management roles by, for example, running courses, no one as far as I am aware has written a text on management specifically for them.

Dr Frada Eskin, who is Director of the Unit for Continuing Education at the University of Manchester, Department of Community Medicine and who in this capacity has been active in organizing management courses for clinicians has now provided such a text.
The stated objective of this book is to identify for the NHS clinician the knowledge and skills relevant to him (sic) in his management role, but this implies a breadth of compass which it does not, in fact, fulfill.

It is simply a text on what the Harvard Business School would call 'Organizational Issues', dealing in its span of 70 pages and 8 substantive chapters with such subjects as teamwork, planning, leadership, group behaviour and the very practical issue of 'Managing Meetings Effectively'.

It is clearly impossible in such a short book to give other than an outline of what is a large subject with an extensive bibliography and for the interested clinician who wishes to pursue it in more depth the references are hardly adequate. However I consider that Dr Eskin has done clinicians a useful service in providing this introductory text. It requires, however, to be accompanied by other similar volumes on other aspects of management to form a comprehensive series for clinicians. If the publishers are not already working on the other volumes, I hope they will take the hint. I can recommend this book to all clinicians whether they plan to become DMT members, DHA members or simply to fight for the survival of their own services even though the relatively high price of $£ 6.95$ will make them think twice about doing so.

\section{P. C. WALKER}

\section{N.E. Thames RHA,} London W2

\section{EEG Technology}

By R. Cooper, J. W. Osselton and J. C. Shaw. 3rd edn. Butterworths, London, Boston, 1981. $£ 16.00$.

This is the third edition of a text which has become the standard indoctrination for workers in the field since the first edition in 1969. Several chapters, particularly relating to electronic technology, evoked potentials and data analysis techniques, have been extensively re-written as indeed was necessary. Primarily addressed to technicians, the contents must be the stock in trade of all who work in clinical neurophysiology. The text is relatively short and precise, there are no frills and little speculation, and the selection of material germane to the task it sets itself and admirably meets.

If there is a criticism, and one wishes in no way to detract from the broad common sense of this volume, then it is that it appears as a follower rather than as a leader in the field. The authors themselves have made notable contributions to the subject and present the stateof-the-art conventional wisdom. As they remark, the introduction of new techniques, CAT scanning in particular, isotope imaging and NMR to come, have none the less left the unique contribution of electrophysiology still in demand. The time is ripe for reappraisal of the role of clinical neurophysiology. EEG departments are by and large relatively dull and unenterprising in their forward look. The leaders of the future, both technicians and clinicians, cut their teeth on this book-what better audience could there be for a little provocative and imaginative prodding on the application of new technology to old and new diagnostic problems? The evoked potential is making an impact, the evaluation of central control and feedback systems ready to go. The whole field has more exciting potential than we have yet seen. Perhaps the authors might pick up the challenge?

\section{B. B. MacGillivray Royal Free Hospital, London NW3}

The Global Eradication of Smallpox. Final Report of the Global Commission for the Certification of Smallpox Eradication

History of International Public Health, no. 4. Pp. 122, illustrated. World Health Organisation, Geneva, 1980. Sw.fr. 11.00.

In 1966 the World Health Assembly started an intensification of the 
smallpox eradication campaign. By 1977 , global eradication appeared imminent. On 8th May 1980 the World Health Assembly accepted the conclusions of the Global Commission for the Certification of Smallpox Eradication; that smallpox eradication had been achieved throughout the world and that there was no evidence that smallpox would return as an endemic disease. This book presents the evidence for the eradication of smallpox.

The Commission's recommendations included discontinuation of smallpox vaccination, continued surveillance of suspected cases of smallpox and research on human monkeypox (a related disease) in West and Central Africa. Educational materials, which were distributed widely, included an 8-page colour pictorial guide, a WHO recognition card and two sets of teaching slides. Systematic vaccination programmes were usually conducted by teams which were often not large. For example, in Kenya 75 staff served 10 million people.

Causes that led to resistance to vaccination were religious beliefs or superstitions, the hostility of minority groups towards vaccinators from other groups and civil disturbances. Great ingenuity and persistence were required to overcome these obstacles. In West Africa as few as $1 \%$ of cases of smallpox were being reported by passive surveillance, but active surveillance was very successful.

Virtually all cases were infected by close contact with patients; aerial transmission over a greater distance was rare. Variolation (deliberate inoculation of susceptible persons with smallpox virus) was responsible for a large number of outbreaks of smallpox. Extensive efforts were made to locate professional variolators and to dissuade them from further practice.

Smallpox was eradicated by a combination of good management, enthusiasm and hard work. The cynic might say that it is the World Health Organisation's only success.

The book is an important record of smallpox eradication. A. HALL Hospital for Tropical Diseases, London NW1

\section{Gynaecological Therapeutics}

Edited by D. F. Hawkins. Pp. viii +287 , illustrated. Bailliere Tindall, London, 1981. £14.50.

This is a companion volume to Obstetric Therapeutics by the same editor. With so many new books on the market dealing with obstetrics and gynaecology, it is difficult to find a niche for a new theme. Professor Hawkins has succeeded in finding an area which has been inadequately dealt with in the past and with this second volume, we have a reasonably priced book at $£ 14.50$ which reviews six topics and is well referenced and indexed. Despite the denigration expressed by the editor in his preface, of super (sub) specialization, two out of the five gynaecological contributors have developed very specialized interests in obstetrics and gynaecology. The book seeks to emphasize the medical aspects of gynaecology which the editor rightly feels have been undervalued and poorly understood. Within the discussion on therapeutics, there is surgical advice where appropriate.

I particularly enjoyed the informative and sympathetic chapter by Sir John Dewhurst on genetic and congenital sexual disorders. The chapter on menstrual disorders could have included mention of high density lipoprotein and more space should have been devoted to the treatment of endometriosis. The menopause is discussed superficially and there is no mention of the role, for instance, of testosterone or of periodic out-patient curettage. The chapter on pelvic infection is a necessary reminder of the severity and mortality associated with pelvic abscess and the approach to its treatment is clearly written. There could have been more discussion of the pros and cons for the prophylactic and therapeutic use of metronidazole. The remaining chapters included the topics of infertility, psychosomatic medicine and treatment of gynaecological cancer. For completeness, I would like to have seen chapters on the medical termination of pregnancy and on the treatment of bladder disorders. The latter is a mine-field of largely ineffective drugs with poorly controlled studies in the literature but also with many innovative methods of treatment. As the drug bill is one of the largest amounts in the annual National Health Service budget, there needs to be some comment on the relationship of cost to effectiveness.

My criticisms are largely minor and should not be seen to detract from a useful text book that should be read by those taking the Membership examination of the Royal College of Obstetricians and Gynaecologists and by those who have already gained it.

S. L. Stanton

St George's Hospital Medical School London SW17

\section{Neurology 1. Clinical Neurophysiology}

Butterworths International Medical Reviews. Edited by E. STALBERG and R. R. Young. Pp. 417, illustrated. Butterworths, London, Boston, 1981. f13.50 (subscription price $£ 10.50$ ).

Billed as the first volume in a new international series of critical reviews, aimed at clinicians and postgraduate trainees presenting new data, trends and major advances, the text meets its objectives. Of its genre, which all too often are expensive ephemera, this book is much better than most; the editors have clearly edited giving the volume a cohesion of purpose which most multi-author compendia so dismally lack.

There is a good short first chapter, by the editors, on what clinical neurophysiology is and more important, what it could be. EMG and peripheral nerve studies are well served in several chapters including analysis of motor units, quantitative methods, neuromuscular transmission, motor performance and sympathetic function. There follow sections on various evoked potentials, all excellent reviews, and the EEG in monitoring coma, epilepsy and sleep states.

The book is not comprehensive of course and not especially for neurophysiologists although they will learn from it. The material is right up to date, the references likewise, the writing good and succinct and production superb. Competent rather than profound, interesting but not seminal. I would estimate its half life at about two years. Within that time span it is an excellent read and a good marker on the present state of the game and cheap at the price.

B. B. MACGILlivRay Royal Free Hospital London NW3

\section{A Physiological Approach to Clinical Neurology}

By J. W. Lance and J. G. MCLeod. 3rd edn. Pp. xiii +380, illustrated. Butterworths, London, 1981. £17.50.

This publication presents a comprehensive account of neurophysiology as a backdrop to the understanding of physical signs and pathology of the nervous system. The text is crisp and well referenced but suffers somewhat from the brevity of the clinical sections. Listing causes of symptoms or signs is of limited clinical value in the absence of an appreciation of the relative importance and frequency of the various conditions.

The book should be very useful to the medical student who wishes to gain an understanding of applied and practical neurophysiology, and also to the graduate in providing an up-to-date refresher course in the normal function of the nervous system. There is a detailed exposition of the basis for and value of the many special 